\title{
Cancer Awareness of a Sample of Malaysian Undergraduate Students
}

\author{
Jo Lin Loo, Wan Yee Woo, Mun Wah Chin, Hui Ru Yam, Yee Kwang Ang, Hip Seng Yim* \\ Faculty of Applied Sciences, UCSI University, Kuala Lumpur, Malaysia \\ *Corresponding author: hsyim@ucsiuniversity.edu.my
}

Received December 31, 2012; Revised February 24, 2013; Accepted February 28, 2013

\begin{abstract}
Cancer is the second cause of premature deaths globally. In Malaysia, a total of 18,219 new cancer cases were diagnosed in 2007. Cancer is preventable and potentially avoidable disease, mainly by tackling modifiable risk factors, increasing participation in cancer screening tests and early detection of cancer through the recognition of early cancer signs. Cancer awareness was assessed using a validated and reliable self-administered questionnaire (Cronbach's alpha coefficient $>0.77$ ) containing 63 items which included awareness (cancer early signs and symptoms, and cancer screening tests); cancer risk factors knowledge; attitude towards cancer prevention; and barriers in seeking cancer and health information. A total of 965 students $(36.0 \%$ males and $64.0 \%$ females) participated with informed consent. Majority of the students were from private universities (73.1\%) while $26.9 \%$ were from public universities. Majority of the students had low awareness (94.4\%) and knowledge (64.9\%) scores but have high attitude scores $(76.9 \%)$. Awareness, knowledge and attitude scores were significantly higher among female students and science faculty students. Only knowledge score was significantly higher among students from Chinese ethnicity. Emotional and practical barriers were determined as the main barrier in seeking medical advice among the participants. This study provides a valuable basis of information toward the formulation of relevant cancer prevention strategies, especially within the scope of health education among the undergraduate students.
\end{abstract}

Keywords: cancer awareness questionnaire (CAQ), knowledge, attitude, barriers, undergraduate students

\section{Introduction}

The cancer mortality statistics in Malaysia have been dramatically elevated in recent years. According to the National Cancer Registry, a total of 18,219 new cancer cases were diagnosed and registered in the year of 2007, which comprised of 8,123 males and 10,096 females. Within the different ethnic groups, cancer seemed to be predominant among Chinese as compared to Malays and Indians [1]. By 2030, it has been expected that the global burden of cancer will increase to 21.4 million new cancer cases and 13.2 million deaths from cancer annually [2].

Cancer is characterized by the abnormal and uncontrollable growth and spread of cells. These cells often undergo a multistep process involving genetic changes, or mutations, tumor growth, invasion and metastasis, ultimately may lead to death [2,3]. During cancer progression, numerous genetic changes and various negative factors may be involved in the molecular basis of metastasis, where several rounds of mutation and selection occurs, resulting in highly invasive ability of some cancer cells. When there is an increase in the expression of metastasis-promoting genes (or decrease in metastasissuppressor genes expression), cancer cells may be provided with a selective invasive advantage which would lead to the clonal outgrowth of tumor $[3,4]$.

More than half of all cancer cases and deaths worldwide are potentially preventable because most of the risk factors that are correlated with cancer are avoidable or modifiable [5]. These include nutritional deficiencies, sedentary lifestyles, obesity, smoking, excessive alcohol consumption and sexually transmitted infections (specifically human papillomavirus). The knowledge and understanding of cancer risk factors and outcome of the disease have an influence on an individual's decisions to participate in prevention and screening behaviors. It has been suggested that higher awareness and knowledge levels are associated with more positive attitude toward the disease [6]. Attitude towards the disease would subsequently impact the behavior of an individual when confronted with the disease [7]. However, most people tend to have poor attitudes and practices towards cancer prevention. Apart from tackling modifiable risk factors, cancer screening was also identified as secondary prevention of cancer. Previous study has shown the effectiveness of cancer screening in reducing the cancer mortality rates [8].

Hence, the aim of this study is to assess cancer awareness among university students, which is prerequisite in planning and designing an effective intervention program.

\section{Methodology}

\subsection{Sample and Procedure}


A cross-sectional study was conducted four private universities and two public universities in Klang Valley, Malaysia. Multistage sampling method was employed in the recruitment of subjects in this study. The universities were randomly selected (via lottery) and letters to request permission to conduct the survey were sent to every faculty (excluding medical sciences faculties) in the universities. In recruiting the student participants, convenience sampling with informed consent was applied. The students were recruited with these inclusion criteria: 1) aged 19-25 years; 2) Malaysian; 3) a current undergraduate student from a non-medical science faculty; 4) English literate; and 5) not being currently diagnosed or have past history of cancer or other chronic diseases.

Ethical clearance to conduct the present study was obtained from the UCSI University's Centre of Excellence for Research, Value Innovation and Entrepreneurship (CERVIE) Research Ethics Committee.

\subsection{Research Instrument}

Cancer awareness was assessed using a validated and reliable self-administered questionnaire (Cronbach's alpha coefficient > 0.77), containing 63 items. The Cancer Awareness Questionnaire (CAQ) consisted of four main sections: Awareness section (early cancer signs and symptoms and cancer screening tests); Knowledge section (cancer risk factors); Attitude section (cancer and cancer prevention); and Barriers in seeking medical advice.

For awareness and knowledge items, categorical responses (true/false/don't know) were used; whereby scores of ' 1 ' was given with correct response, while ' 0 ' was given for incorrect or don't know responses [9]. The Likert scales that were applied for the attitude items include 'strongly agree'; 'agree'; 'don't know'; 'disagree'; and 'strongly disagree'. For positive attitude items, scores of ' $4=$ strongly agree', ' $3=$ agree', ' $2=$ don't know', ' $1=$ disagree' and ' $0=$ strongly disagree' were given. The reversed scoring was used for negative attitude items [10]. Lastly, items on the barriers in seeking medical advice section had ordinals responses, namely, 'yes often'; 'yes sometimes'; 'no'; and 'don't know'. Responses with 'yes often' and 'yes sometimes' were awarded with a score of ' 1 ', while responses like 'no' and 'don't know' responses were scored ' 0 ' [11].

\subsection{Statistical Analyses}

Data were analyzed using the PASW version 18.0 (SPSS Inc., 2012). Descriptive statistics (e.g. mean and standard deviation) were used to describe continuous variables, while categorical variables were presented in frequencies and percentages. Independent sample t-test was used to determine the mean score differences of the awareness, knowledge and attitudes sections between genders, universities and faculties. One-way ANOVA was used to determine the difference of awareness, knowledge and attitude mean scores among ethnic groups. Statistical significance was determined at $\mathrm{p}<0.05$.

\section{Results}

\subsection{Demographic Characteristics}

A total of 965 undergraduate students were recruited from four private universities and two public universities in Klang Valley, Malaysia. The students were within the age range of 19-25 years (mean age of $20.70 \pm 1.59$ years). In terms of ethnicity, $32.8 \%$ were Malays, $60.7 \%$ were Chinese, $5.2 \%$ were Indians and $1.2 \%$ was from other ethnic groups. Majority of the participants were females $(64.0 \%)$, from private universities $(73.1 \%)$ and from nonscience faculties $(77.8 \%)$. In addition, approximately half $(56.4 \%)$ of the participants had a monthly household income (or allowance) below RM2,000 ( $\approx$ USD650).

Table 1. Socio-Demographic and Economic Information of Participants (n=965)

\begin{tabular}{|c|c|}
\hline Description & $\mathrm{n}(\%)$ \\
\hline Age & \\
\hline 19-21 years old & $719(74.5)$ \\
\hline $22-25$ years old & $246(25.5)$ \\
\hline \multicolumn{2}{|l|}{ Ethnicity } \\
\hline Malay & $317(32.8)$ \\
\hline Chinese & $586(60.7)$ \\
\hline Indian & $50(5.2)$ \\
\hline Others & $12(1.2)$ \\
\hline \multicolumn{2}{|l|}{ Gender } \\
\hline Male & $347(36.0)$ \\
\hline Female & $618(64.0)$ \\
\hline \multicolumn{2}{|l|}{ University } \\
\hline Private & $705(73.1)$ \\
\hline Public & $260(26.9)$ \\
\hline \multicolumn{2}{|l|}{ Faculty } \\
\hline Science & $214(22.2)$ \\
\hline Non-science & $751(77.8)$ \\
\hline \multicolumn{2}{|l|}{ Monthly Household Income/Allowance } \\
\hline Below RM2,000 ( $\approx$ USD650) & $544(56.4)$ \\
\hline 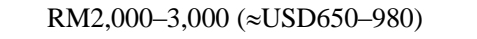 & $159(16.5)$ \\
\hline RM3,000-4,000 ( $\approx$ USD980-1,300) & $102(10.6)$ \\
\hline RM4,000-5,000 ( $\approx$ USD1,300-1,630) & $59(6.1)$ \\
\hline 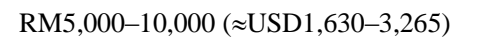 & $72(7.5)$ \\
\hline Above RM10,000 ( $\approx$ USD3,265) & $29(3.0)$ \\
\hline
\end{tabular}

Exchange rate: $\mathrm{RM} 1 \approx \mathrm{USD} 0.32$.

\subsection{Awareness, Knowledge and Attitude Sections}

The Awareness section consisted of items on cancer early signs and symptoms, and cancer screening tests. The most recognized symptoms were 'persistent unexplained pain' (65.4\%), 'unexplained weight loss' (61.8\%) and 'unexplained lump or swelling' (58.0\%). However, awareness on items 'persistent difficulty swallowing' and 'change in appearance of mole' were relatively low, whereby only $35.5 \%$ and $35.2 \%$ of participants respectively have heard about it. The awareness of cancer screening tests was generally low, except for items 'breast self-examination' (71.8\%), 'ultrasound' (63.5\%) and 'clinical breast examination' (56.6\%).

In the Knowledge section, there were items on modifiable risk factors (diet, body weight management and lifestyle) and non-modifiable risk factors (genetic). More than $90 \%$ of the students were able to recognize tobacco use as a risk factor. Approximately $60-70 \%$ of the participants answered correctly for most of the diet, body weight management and lifestyle items. However, only less than half of the participants correctly answered items such as 'body and abdominal fatness increases the risk of cancer' $(44.0 \%)$, 'sun exposure between $10 \mathrm{am}$ to $4 \mathrm{pm}$ 
increases the risk of cancer' $(40.6 \%)$ and 'HPV infection increases the risk of cancer' $(33.3 \%)$.

In Table 2, results of good score level (having at least $70 \%$ correct answers) in the Awareness; Knowledge and Attitude sections were presented. Based on the results, participants had low awareness and knowledge levels. Only 5.6\% had high awareness levels on early cancer symptoms and cancer screening tests, while $35.1 \%$ had high knowledge levels on cancer risk factors. However, results show that $76.9 \%$ of participants obtained a good score level in the attitude section.

Table 2. Score Level of Awareness, Knowledge and Attitude Sections $(\mathbf{n}=965)$

\begin{tabular}{|c|c|c|}
\hline \multirow{2}{*}{ Sections } & \multicolumn{2}{|c|}{ Score level, n (\%) } \\
\cline { 2 - 3 } & Good & Poor \\
\hline Awareness & $54(5.6)$ & $911(94.4)$ \\
\hline Knowledge & $339(35.1)$ & $626(64.9)$ \\
\hline Attitude & $742(76.9)$ & $223(23.1)$ \\
\hline
\end{tabular}

Good score refers to $\geq 70 \%$.

Independent $t$-test was conducted to compare the awareness, knowledge and attitude scores between males and females (Table 3). Females had significantly higher scores compared to their male counterparts in the awareness section $(\mathrm{t}(662)=-4.11, \mathrm{p}<0.01)$, knowledge section $(\mathrm{t}(963)=-2.80, \mathrm{p}<0.05)$ and attitude section $(\mathrm{t}$ $(963)=-3.31, \mathrm{p}<0.05)$. When comparing between private and public universities, participants from private universities had significantly higher scores than public university students in the knowledge section $(\mathrm{t}(963)=$ 2.37, $\mathrm{p}<0.05)$, but their scores in the awareness $(\mathrm{t}(963)=$ $1.17, \mathrm{p}>0.05)$ and attitude $(\mathrm{t}(963)=-1.17, \mathrm{p}>0.05)$ sections did not differ significantly. Results also showed that sciences students had significantly higher awareness $(\mathrm{t}(401)=8.21, \mathrm{p}<0.01)$, knowledge $(\mathrm{t}(387)=9.35, \mathrm{p}<$ $0.01)$ and attitude $(\mathrm{t}(416)=4.82, \mathrm{p}<0.01)$ scores compared to students from non-science faculties.

Table 3. Difference of Awareness, Knowledge and Attitude Scores between Genders, Universities and Faculties (n=965)

\begin{tabular}{|c|c|c|c|}
\hline Categories & $\begin{array}{l}\text { Awareness } \\
\text { Score }\end{array}$ & $\begin{array}{l}\text { Knowledge } \\
\text { Score }\end{array}$ & $\begin{array}{l}\text { Attitude } \\
\text { Score }\end{array}$ \\
\hline $\begin{array}{c}\text { Gender } \\
\text { Male }(n=347) \\
\text { Female }(n=586)\end{array}$ & $\begin{array}{c}7.38 \pm 4.56^{* *} \\
8.60 \pm 4.15\end{array}$ & $\begin{array}{c}11.44 \pm 3.46^{*} \\
12.09 \pm 3.45\end{array}$ & $\begin{array}{c}29.94 \pm 4.65 * \\
30.94 \pm 4.42\end{array}$ \\
\hline $\begin{array}{c}\text { University } \\
\text { Private }(n=705) \\
\text { Public }(n=260)\end{array}$ & $\begin{array}{l}8.26 \pm 4.28 \\
7.89 \pm 4.51 \\
\end{array}$ & $\begin{array}{c}12.01 \pm 3.45^{*} \\
11.42 \pm 3.48\end{array}$ & $\begin{array}{l}30.47 \pm 4.48 \\
30.86 \pm 4.65\end{array}$ \\
\hline $\begin{array}{c}\text { Faculty } \\
\text { Science }(\mathrm{n}=214) \\
\text { Non-science } \\
(\mathrm{n}=751)\end{array}$ & $\begin{array}{c}10.24 \pm 3.65^{* *} \\
7.57 \pm 4.34\end{array}$ & $\begin{array}{c}13.72 \pm 2.97 * * \\
11.32 \pm 3.41\end{array}$ & $\begin{array}{c}31.88 \pm 3.77 * * \\
30.21 \pm 4.66\end{array}$ \\
\hline
\end{tabular}

Results were presented as mean \pm standard deviation.

Significant difference between groups at $* \mathrm{p}<0.05 ; * * \mathrm{p}<0.01$.

Table 4. Difference of Awareness, Knowledge and Attitude Scores between Ethnic groups $(\mathbf{n}=965)$

\begin{tabular}{|c|c|c|c|}
\hline Categories & $\begin{array}{c}\text { Awareness } \\
\text { Score }\end{array}$ & $\begin{array}{c}\text { Knowledge } \\
\text { Score }\end{array}$ & $\begin{array}{c}\text { Attitude } \\
\text { Score }\end{array}$ \\
\hline $\begin{array}{c}\text { Malay } \\
(\mathrm{n}=317)\end{array}$ & $7.84 \pm 4.44$ & $11.04 \pm 3.50$ & $30.42 \pm 4.83$ \\
\hline $\begin{array}{c}\text { Chinese } \\
(\mathrm{n}=586)\end{array}$ & $8.41 \pm 4.28$ & $12.47 \pm 3.30 * *$ & $30.72 \pm 4.30$ \\
\hline $\begin{array}{c}\text { Indian } \\
(\mathrm{n}=50)\end{array}$ & $7.00 \pm 3.94$ & $10.48 \pm 3.33$ & $29.60 \pm 4.86$ \\
\hline $\begin{array}{l}\text { Others } \\
(\mathrm{n}=12)\end{array}$ & $9.33 \pm 5.50$ & $8.92 \pm 3.83$ & $31.67 \pm 5.74$ \\
\hline
\end{tabular}

Results were presented as mean \pm standard deviation.

**Significantly higher than other ethic $(\mathrm{p}<0.01)$.

A one-way ANOVA was a carried out to compare the awareness, knowledge and attitude scores among ethnic groups (Table 4). In the awareness section, no significant difference was found among the ethnic groups (F $(3,961)$ $=2.72, \mathrm{p}>0.05)$. In the knowledge section, the mean

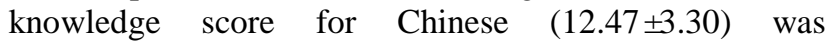
significantly higher than that of Malays (11.04 \pm 3.50$)$, Indians (10.48 \pm 3.33$)$ and other $(8.92 \pm 3.83)$ ethnic groups $(\mathrm{F}(3,961)=18.52, \mathrm{p}<0.01)$. However, knowledge scores among Malays, Indian and other ethnic groups did not differ significantly. In the attitude section, the attitude scores among ethnic groups did not differ significantly ( $F$ $(3,961)=1.33, \mathrm{p}>0.05)$.

\subsection{Barriers in Seeking Medical Advice}

In the 'Barriers in seeking medical advice' section, the number of participants who responded 'yes often' or 'yes sometimes' were determined as shown in Table 5. The different barriers were categorized into three groups, namely emotional, practical and service barriers. The main barrier category that was identified was emotional barriers, which included 'too scared' (62.3\%), 'worried about what the doctor may find' (61.5\%), 'would not feel confident talking about symptom' (48.4\%) and 'too embarrassed' $(44.1 \%)$. Other barriers to highlight included two practical barriers, 'too busy to make time' $(57.2 \%)$ and 'too many other things to worry about' (56.0\%), and a service barrier, 'worried about consultation fees' (60.4\%).

Table 5. Barriers in Seeking Medical Advice Endorsed (\% responding 'yes often' or 'yes sometimes') $(n=965)$

\begin{tabular}{|c|c|}
\hline Barriers in seeking medical advice & $\begin{array}{c}\text { Endorsement } \\
(\%)\end{array}$ \\
\hline \multirow{5}{*}{$\begin{array}{c}\text { Emotional barriers } \\
\text { Too scared } \\
\text { Worried about what the doctor may find } \\
\text { Would not feel confident talking about the } \\
\text { symptom } \\
\text { Too embarrassed }\end{array}$} & \\
\hline & 62.3 \\
\hline & 61.5 \\
\hline & 48.4 \\
\hline & 44.1 \\
\hline Practical barriers & \\
\hline Too busy to make time & 57.2 \\
\hline Too many other things to worry about & 56.0 \\
\hline Difficult to arrange transport & 34.6 \\
\hline Service barriers & \\
\hline Worried about the consultation fees & 60.4 \\
\hline Difficult to make appointment with doctor & 34.8 \\
\hline Doctor would be difficult to talk to & 24.4 \\
\hline Worried about wasting doctor's time & 12.2 \\
\hline
\end{tabular}

\section{Discussion}

This study investigated the awareness (early cancer symptoms and screening tests); knowledge (cancer risk factors); attitude (cancer and cancer prevention); and barriers (in seeking medical advice) among undergraduate university students. The overall results revealed that the majority of the students had low awareness and knowledge levels, while having positive attitude levels at the same time.

The findings of this study were in agreement with various studies that have been carried out in Malaysia on the awareness and knowledge levels of specific, common cancers. Harmy et al. [12] reported that West Malaysians had low knowledge regarding colorectal cancer and screening. Similarly, Nik Rosmawati [10] advised that Malaysian women lacked awareness and knowledge of early cancer signs. Hashim et al. [13] conducted a study among patients with rectal bleeding revealed that the $68 \%$ 
of patients who correctly identified their condition as a symptom of cancer were not aware of the best screening method to detect colorectal cancer. In another study, results revealed poor understanding of cancer risk factors and signs and symptoms in addition to misconceptions about breast cancer treatments [14].

The lack of awareness levels found in this study revealed that undergraduate students generally are ignorant towards early cancer symptoms and screening tests. Besides the well-recognized symptoms such as unexplained pain, weight loss and lump/swelling, many participants are unaware of the other early cancer symptoms including persistent cough and difficulty swallowing, change in appearance of mole, and sore that does not heal. The findings of these poorly recognized symptoms were also similar to a study by Keeney et al. [15]. Efforts to increase the awareness of early cancer symptoms should place emphasis on the unrecognized symptoms, as it has been suggested that awareness of early cancer symptoms could contribute to early cancer detection [16].

In recent years, majority of the cancer awareness campaigns in Malaysia focused mainly on breast cancer, as breast cancer is the most frequent cancer in Malaysia [1]. The success of extensive campaigns by several organizations (e.g. National Cancer Council (MAKNA), National Cancer Society Malaysia, and Breast Cancer Welfare Association Malaysia) on breast cancer awareness are partly reflected in the students' awareness of screening tests associated with breast cancer (breast selfexamination and clinical breast examination). Another recent campaign was on focused cervical cancer, however, awareness of screening test for cervical cancer (Pap smear) was still low (26.1\%) among the students.

Overall, knowledge of cancer risk factors among the undergraduates was low with the exception of tobacco use. Poor knowledge was particularly regarding items related to lifestyle (e.g. stress and sun exposure between 10am and $4 \mathrm{pm}$, and their association with cancer). Public health campaigns may focus on increasing the awareness of these risk factors as it is important to help the public better understand the link between lifestyle and cancer. Increasing public awareness in turn could motivate healthy lifestyle practices, which will contribute in lowering cancer incidence as well as other chronic diseases [17].

Majority of the students $(74.7 \%)$ had positive attitudes towards cancer and cancer prevention, which is essential for behavioral modification. A study by Tan et al. [18] also demonstrated similar findings, in which university students had positive attitudes towards cancer prevention. Having a positive attitude may help a person to be more accepting and receptive towards education and intervention initiatives.

Based on the findings of this study, students who were female and from science faculties demonstrated significantly higher awareness, knowledge and attitude scores compared to males and non-science students. These results were in agreement to the findings of another study on cancer knowledge, attitude and practices which was carried out among young Malaysians aged between 18 and 27 years [19]. The score differences between genders may be due to the fact that females are more involved in cancer detection actions [20], particularly because cancer prevention campaigns have focused mainly on breast and cervical cancers which involves only females. As for students from science faculties, they may have higher exposure towards health information, explaining their higher scores compared to non-science students.

The Chinese students in this study had significantly higher knowledge on cancer risk factors in comparison to the other ethnic groups. This result is consistent with that of Tan et al. [18]. The score differences across the ethnic groups may be explained by the difference in tradition, beliefs and lifestyles. In addition, Chinese students may inquire more knowledge on cancer risk factors as cancer is more predominant among the Chinese [1] than the other ethnic groups. This could cause Chinese students to be more concerned and seek more information on cancer prevention [18].

In this study, participants have identified several emotional and practical barriers as the main barriers in seeking medical advice when they notice a warning sign of cancer. This finding is similar to previous studies carried out in the UK [16,21]. Among the emotional barriers, being 'too scared' and 'worried about what the doctor may find' were the most endorsed barriers by the participants. This may imply that undergraduates are unaware of the early diagnosis benefits and efficacy of many cancer treatments [11]. The practical barriers which were also highly endorsed were being 'too busy' and having 'too many things to worry about'. These suggest that some participants may not feel that their symptom is important and deserving of any medical attention. Another noteworthy barrier is a service barrier, which is 'worried about the consultation fees'. This could be explained by the age group of the population being studied, as the participants are students and who may not have their own income.

\section{Conclusion}

In conclusion, the findings of this study revealed that the awareness of cancer early symptoms and screening tests, and knowledge of cancer risk factors of a sample of undergraduate students in the Klang Valley, Malaysia were low, but attitude towards cancer and cancer prevention was high among the undergraduate students. Awareness, knowledge and attitude scores were significantly higher among female students and science faculty students. Only knowledge score was significantly higher among students from private universities and Chinese ethnicity. Emotional and practical barriers were determined as the main barrier in seeking medical advice among the participants. This study provides a valuable basis of information toward the formulation of relevant cancer prevention strategies, especially within the scope of health education among the undergraduate students.

\section{Acknowledgements}

The authors would like to thank UCSI University Research Grant Scheme for the financial support (Proj-InFAS-011). 


\section{Authors Disclosure Statement}

The authors have no competing interests.

\section{References}

[1] National Cancer Registry (NCR), Malaysia, National cancer registry report: Malaysia cancer statistics - data and figure 2007, Ministry of Health, Malaysia, 2007.

[2] American Cancer Society (ACS). Global cancer facts \& figures, 2nd edition, American Cancer Society, Atlanta, 2011.

[3] Shih, J.Y., Yuan, A., Chen, J.J.W. and Yang, P.C, "Tumorassociated macrophage: Its role in cancer invasion and metastasis," J Cancer Molecules, 2(3). 101-106. 2006.

[4] Yokota, J, "Tumor progression and metastasis," Carcinogenesis, 21(3). 497-503. 2000.

[5] Stein, C.J. and Colditz, G.A, "Modifiable risk factors for cancer," Br J Cancer, 90(2). 299-303. 2004.

[6] McCaffery, K., Wardle, J. and Waller, J, "Knowledge, attitudes, and behavioral intentions in relation to the early detection of colorectal cancer in the United Kingdom," Prev Med, 36(5). 525 535. 2003.

[7] Miller, M., Kearney, N. and Smith, K, "Measurement of cancer attitudes: A review," Eur J Oncol Nurs, 4(4). 233-245. 2000.

[8] Park, S., Bae, J., Nam, B.H. and Yoo, K.Y, "Aetiology of cancer in asia," Asian Pacific J Cancer Prev, 9(3). 371-380. 2008.

[9] Cancer Research UK, Cancer awareness measure (CAM) toolkit (version 2), Cancer Research UK, University College London, Kings College and University of Oxford, 2008.

[10] Nik Rosmawati, N.H, "Knowledge, attitude and practice of breast self-examination among women in suburban area in Terengganu, Malaysia," Asian Pacific J Cancer Prev, 11. 1503-1508. 2010.

[11] Waller, J., Robb, K., Stubbings, S., Ramirez, A., Macleod, U., Austoker, J., Hiom, S. and Wardle, J, "Awareness of cancer symptoms and anticipated help seeking among ethnic minority groups in England," Br J Cancer, 101 (S2). S24-S30. 2009.

[12] Harmy, M.Y., Norwati, D., Norhayati, M.N. and Amry, A.R "Knowledge and attitude of colorectal cancer screening among moderate risk patients in West Malaysia," Asian Pacific J Cancer Prev, 12(8). 1957-1960. 2011.

[13] Hashim, S., Tong, S.F., Omar, K., et al, "Knowledge of colorectal cancer among patients presenting with rectal bleeding and its association with delay in seeking medical advice," Asian Pacific $J$ Cancer Prev, 12(8). 2007-2011. 2011.

[14] Al Dubai, S.A.R., Ganasgeran, K., Alabsi, A.M., Alshagga, M.A. and Ali, R.S, "Awareness and Knowledge of oral cancer among university students in Malaysia," Asian Pacific J Cancer Prev, 13 (1). 165-168. 2012.

[15] Keeney, S., McKenna, H., Fleming, P. and McIlfatrick, S, “An exploration of public knowledge of warning signs for cancer," Eur J Oncol Nurs, 15 (1). 31-37. 2011.

[16] Robb, K., Stubbings, S., Ramirez, A., et al, "Public awareness of cancer in Britain: A population-based survey of adults," $\mathrm{Br} J$ Cancer, 101(S2). S18-S23. 2009.

[17] Power, E., Simon, A., Juszcyk, D., Hiom, S. and Wardle, J, "Assessing awareness of colorectal cancer symptoms: Measure development and results from a population survey in the UK," Bio Med Central, 11(1). 366-375. 2011.

[18] Tan, Y.Y., Hesham, R. and Qodriyah, H.M.S, "Knowledge and attitude of university students in health sciences on the prevention of cervical cancer," Med J Malaysia, 65(1). 53-57. 2010.

[19] Al-Naggar, R.A. and Chen, R, "Nutrition and cancer prevention: Knowledge, attitudes and practices among young Malaysians,' Asian Pacific J Cancer Prev, 12(3). 691-694. 2011

[20] Nooijer, J., Lechner, L. and Vries, H, "Early detection of cancer: Knowledge and behavior among Dutch adults," Cancer Detect Prev, 26(5). 362-369. 2002

[21] Simon, A.E., Waller, J., Robb, K. and Wardle, J, "Patient delay in presentation of possible cancer symptoms: The contribution of knowledge and attitudes in a population sample from the United Kingdom," Cancer Epidemiol Biomarkers Prev, 19(9). 2272-2277. 2010 